\title{
Inferior Palpebral Vein
}

National Cancer Institute

\section{Source}

National Cancer Institute. Inferior Palpebral Vein. NCI Thesaurus. Code C53049.

The blood vessels that drain blood from the inferior eyelid into the angular vein. 